2008

\title{
Addressing the Global Tragedy of Needless Pain: Rethinking the United Nations Single Convention on Narcotic Drugs
}

Allyn L. Taylor

Georgetown University Law Center, alt28@law.georgetown.edu

This paper can be downloaded free of charge from:

http://scholarship.law.georgetown.edu/ois_papers/6 


\section{Addressing the Introduction}

Global Tragedy of

Needless Pain:

Rethinking the

United Nations

Single Convention

on Narcotic Drugs

Allyn L. Taylor

Important medical advances over the last several decades have vastly improved the technical capacity to control human pain. Millions of patients suffering from cancer, HIV/AIDS, and other conditions have been able to find relief from incapacitating chronic and acute pain. However, despite these developments, pain remains severely under treated worldwide, particularly in developing countries. The tragic consequence is that for millions of people around the globe, excruciating pain is an inescapable reality of life.

Medical availability of effective pain medication is undoubtedly one of the most neglected realms of global public health. Over the last few years, public and scholarly attention has centered on the important issue of access to medicines, particularly in the context of HIV/AIDS antiretroviral therapy (ARV). Unfortunately, the global attention to ARV therapy has not stimulated broader attention to the universal issue of human pain that plagues millions of persons around the globe with terminal, chronic, and acute conditions. The lack of pain management options for marginalized populations is an enduring and expanding global health calamity.

The failure of national governments to prioritize access to opioid analgesics for pain, and the complex socioeconomic, cultural, and regulatory factors contributing to the underutilization of pain medicine in developing countries, are widely documented. ${ }^{1}$ Notably, however, there has been no scholarly consideration of the global drug regulatory environment or how international law and international institutions either interfere with or can contribute to national efforts to strengthen pain management. Opium is not only integral to the relief of individual pain, but it is also an internationally regulated substance under the 1961 United Nations Single Convention on Narcotic Drugs (Single Convention). ${ }^{2}$

The goals of this article are twofold: (1) to critically analyze the impact of the international drug regulatory regime on medical availability of narcotic drugs and (2) to consider legal and institutional mechanisms that can be employed globally to promote wider accessibility of these critical medicines. The United Nations international drug control regime, including the Single

Allyn L. Taylor, J.D., LL.M., J.S.D., is a Visiting Professor of Law at the O'Neill Institute for National and Global Health Law at Georgetown University Law Center and an Adjunct Professor of International Relations at the Paul $H$. Nitze School of Advanced International Studies at Johns Hopkins University. She has been a Health Policy Adviser at the World Health Organization in Geneva, Switzerland and a Legal Consultant to the WHO Department of Medicines Policy and Standards. 
Convention and the international organizations that support it, is traditionally understood to focus on the criminalization of drug abuse. It typically has not been regarded as a mechanism to provide a global framework to advance medical availability of opioids. However, ensuring medical availability of narcotic drugs for medicinal purposes constitutes a key but neglected aim of the international legal regime. This article con- wide $^{6}$ - countries in which the need for pain medicine is large and growing. Of the 57 million people who die annually, approximately six million deaths are from cancer and three million are from HIV/AIDS, with the majority of such deaths occurring in developing states. ${ }^{7}$ Notably, the majority of people lacking access to opioid analgesics have a heightened need for such medication because of a relative lack of access to cura-

\section{While morphine and other opioid analgesics are largely available in the United States, Western Europe, Australia, and New Zealand, they are in critically short supply in developing countries, newly industrializing countries, and formerly socialist states. Poor countries, which comprise about 80 percent of the world's population, account for only about six percent of global consumption of morphine.}

tends that a more balanced approach to international implementation of the Single Convention on Narcotic Drugs - one that weighs the Convention's dual goals of controlling abuse and ensuring availability - can have an important, albeit limited, influence on states in encouraging medical availability of opioids.

\section{Pain and Pain Management in Global Perspective}

Today we have the knowledge to provide highly effective pain relief to improve the quality of life and conditions of death for millions of people suffering from cancer, HIV/AIDS, chronic conditions, post-surgical pain, and other agonizing illnesses. Tragically, however, only a small percentage of the world's population that could benefit from pain relief has access to such services. According to the World Health Organization (WHO), 80 percent of persons worldwide suffering from severe pain do not receive adequate treatment. ${ }^{3}$

Despite the global scale of the human suffering caused by lack of access to morphine and other opioid analgesics, many countries have yet to recognize pain management as an important public health concern. While morphine and other opioid analgesics are largely available in the United States, Western Europe, Australia, and New Zealand, they are in critically short supply in developing countries, newly industrializing countries, and formerly socialist states. ${ }^{4}$ Poor countries, which comprise about 80 percent of the world's population, account for only about six percent of global consumption of morphine. ${ }^{5}$

WHO estimates that severe under treatment for pain is an acute problem in more than 160 countries world- tive or palliative care, such as surgery, chemotherapy, radiotherapy, or anti-retroviral drugs in poor states. ${ }^{8}$ Millions of others suffering from moderate to severe pain from other causes, including chronic illnesses such as diabetes, heart disease, and lung disease, also receive no pain management.

Pain control is designed to minimize physical discomfort and allow patients to function normally. There are a number of different interventions for pain relief, including drugs and radiotherapy, as well as anesthetic, neurosurgical, psychological, and behavioral approaches. However, morphine and other opioid analgesics are the only effective analgesia for a wide variety of conditions, including cancer pain, chronic pain, diabetic neuropathy, HIV neuropathy, sickle cell disease, surgical pain, and traumatic pain..$^{9}$ Morphine has also been recognized by $\mathrm{WHO}$ as an essential medicine since the elaboration of the first Model List of Essential Medicines in $1977 .^{10}$

The importance of opioids as analgesic medication for the management of moderate and severe pain is well understood. Significant advances in pharmacology and technology over the last several decades have improved our capacity to control pain. Although the field of pain management is still evolving, the development of well-crafted protocols has brought relief to the suffering of millions and allowed persons with terminal illnesses to die in relative comfort. ${ }^{11}$ Opioid analgesics have been recognized by WHO as absolutely safe, effective, and essential for the management of cancer pain. ${ }^{12}$ Research has shown that WHO's three-step model analgesic method for cancer pain relief is effective in 90 percent of cancer patients. ${ }^{13}$ 
In the future, the global need for pain medicine will increase rapidly. In developed and developing countries, the world's population is aging, resulting in an increase of the prevalence of chronic, painful conditions and cancer. By 2025, there will be 1.2 billion people over the age of 60 , which is double the current estimate of 600 million. ${ }^{14}$ Future demand for such care is also expected to rise due to the dramatically expanding prevalence of HIV/AIDS in several parts of the world. Tragically, the greatest need for pain relief is increasingly concentrated in developing countries, where access to morphine and other opioid analgesics is inadequate or non-existent. For example, WHO estimates that the burden of cancer will increasingly shift from industrialized countries to developing states, so that by the year 2020, 70 percent of the estimated 20 million new cancer cases will occur in developing states. ${ }^{15}$

In order to address the global challenge of managing pain, vastly strengthened national and international action is necessary. In the absence of more effective approaches to pain management, WHO estimates that 600 million people alive today will experience negative health impacts during their lifetime as a result of the inability to obtain access to effective pain medicine. ${ }^{16}$

\section{National Challenges to Medical Availability}

Improving quality of life and the circumstances surrounding death and dying through equitable access to pain management requires an appreciation of the multiple barriers that exist, nationally and internationally, to providing analgesics. At the national level, a number of complex socio-economic, cultural, ethical, and political factors coalesce to generate substandard conditions for pain management. ${ }^{17}$

In developing nations, pain management must be understood within the context of underlying conditions of poverty and underdevelopment. Basic pain management must compete for scarce resources and political attention with other primary health care services as well as with other social concerns, such as education, food, and transportation. ${ }^{18}$ Poverty and underdevelopment affect both national health policies as well as individual access to pain services. In developing nations, opioid availability is typically limited to specialty centers; opioids are largely delivered parenterally to hospitalized patients, and dispensation is restricted to a select group of health care providers. ${ }^{19}$ Additionally, economic factors merge with demographic and geographical barriers to further obstruct availability of medicinal opium. For example, patients who cannot afford medication, or who are unable to travel to centers designated for treatment, are excluded from care. In many countries, over half of the population will never encounter a nurse or doctor in their lifetime. ${ }^{20}$

The economic, demographic, and geographical obstacles to pain management are compounded by the inflated costs of opioid analgesics in developing nations. Morphine is a low-cost, effective pain relief medicine ideally suited for poor countries. It is inexpensive to manufacture, costing approximately one American cent for each ten milligrams of generic morphine sulfate tabulate or morphine hydrochloride solution. ${ }^{21}$ Thus, unlike the global political battle over access to antiretroviral medicine for HIV/AIDS that has dominated public debates during this decade, patents and pricing should not be a major barrier to opioid availability. However, pharmaceutical companies often supply more expensive opioid formulations in developing countries, thus limiting their capacity to obtain cheap oral morphine. ${ }^{22}$ Ironically, research indicates that the cost of pain medication in developing countries exceeds the cost in industrialized states. $^{23}$

In addition to economic factors, cultural attitudes and knowledge barriers contribute to the under treatment of severe pain. ${ }^{24}$ The notion that individual pain is a private matter to be endured without complaint is widely held. ${ }^{25}$ This attitude of silent suffering can be compounded by cultural and ethnic differences among patients and providers. These differences can create communication gaps and cultural barriers, which impede the recognition and treatment of severe pain.

Furthermore, in many cultures, patients hold an irrational fear that opioid addiction will result from use during appropriate pain management. Research has soundly established that addiction is rare after using a powerful opioid analgesic for a legitimate medical purpose and that opioid analgesics are a core component of good clinical practice. In short, the medical use of opioids does not create addicts, while undue limitations on medical use of opioids hurts patients. ${ }^{26}$ However, the mistaken link between addiction and medical usage of opioid analgesics persists.

Similarly, a lack of training and basic education in the use of opioids has also created an irrational fear of addiction or misuse of opioid analgesics among health care professionals. This problem is found in both industrialized and developing countries and usually leads to the under treatment of pain. ${ }^{27}$ Consequently, it is widely recognized that integration of pain management training in the undergraduate and continuing education of doctors, nurses, and other allied health professionals in nations worldwide is a critical factor in efforts to widen pain treatment worldwide. ${ }^{28}$ 
Perhaps the most important national barrier to the access to opioid analgesics is the absence of government commitment, including the commitment to encourage or facilitate availability and appropriate education of health care professionals. In resourcelimited settings, medical availability of opioids is often considered a low clinical and political priority. Pain relief for the terminally, critically, and chronically ill must compete for limited resources against programs aimed at the prevention and treatment of disease in the young and healthy. Consequently, funds allotted for medical availability of opioids are often limited. ${ }^{29}$

Many governments in developing countries do not recognize palliative care, including access to opioid analgesics to relieve suffering, as a national health care priority. The absence of political will to support effective pain management is evidenced by the fact that only a handful of poor countries have implemented WHO's recommendation to adopt a national policy that integrates palliative care into the existing health system. In Africa, for example, Uganda was the only country in 2002 to prioritize palliative care, including access to pain medication for persons with HIV/AIDS and cancer, in its national health plan. ${ }^{30}$

The absence of political will to support the availability of pain relief medication is also evident in the overregulation of medicinal opium, an unremitting and critical problem that interferes with the availability of powerful analgesics in many poor countries. ${ }^{31}$ Governments worldwide hold a legitimate concern about the diversion of licit medicines into illegal channels. In many countries, however, the regulatory response has not been narrowly tailored to ensure that concerns of law enforcement do not unduly interfere with medical availability. As a consequence, opioid distribution is so tightly regulated that it can become too burdensome or difficult for health care providers to offer their patients effective pain control. Overwhelming prescription-filing requirements, inappropriate restrictions on the amount and duration of prescriptions, and other practices that interfere with clinical practice are common. For example, in India, a health facility planning on dispensing opioids must scale a number of cumbersome and time-consuming regulatory hurdles. It must obtain an opioid possession license, as well as government license forms for opioid purchase, transport, and import, in order to legally dispense it. ${ }^{32}$ To further compound the difficulties of access, prescriptions for oral morphine cannot, by law, be filled at commercial pharmacies. Only a limited number of tertiary and cancer hospitals hold such licenses, so that consequently, the vast majority of rural inhabitants in India do not have access to effective pain relief. ${ }^{33}$ In Kerala, an Indian state of over 30 million people, only three major health facilities dispense oral morphine. ${ }^{34}$ Although much of the world's supply of morphine comes from India, overregulation means that only a trickle of the production is made available to patients there. $^{35}$

The failure of governments to prioritize access to opioid analgesics and the complex national socioeconomic, cultural, and regulatory factors contributing to the underutilization of pain medicine in developing countries are widely understood. A number of organizations, including WHO and the Pain and Policy Studies Group, a WHO collaborating center, work with countries to improve the policy environment for treating patients with pain. In February 2007, WHO substantially increased its commitment to advance the medical availability of opioid analgesics by launching a new program designed to support national efforts in ensuring adequate availability of opioid analgesics for pain treatment for their populations. ${ }^{36}$ The new WHO Access to Controlled Medications Programme will work with states to address a number of the critical national factors that interfere with medical availability. Among other things, this programme will include the following: (1) review of relevant national legislation and administrative procedures; (2) promotion of continuing medical education and rational use of controlled medications by health care professionals; and (3) assistance in ensuring an uninterrupted supply of opioid analgesics at affordable prices. Given the scope of the global public health concern, it is critical to enhance the technical and regulatory capacity of governments in order to advance medical availability of opioid analgesics. Innovative and strengthened approaches to advance patient access to pain medicine are urgently needed.

\section{The Impact of International Law and Institutions on the Medical Availability of Opioids}

While important advances have been made in identifying the national regulatory factors that impede access to pain medication, the impact of the international regulatory environment on medical availability of opioid analgesics, and the global mechanisms that can be adopted to promote national efforts to provide effective pain medicine, have thus far received limited scholarly and public attention. Morphine and other opioid analgesics are not only central to pain management, they are also controlled substances under a complex United Nations drug regulatory regime. As described herein, the regulatory scheme established by the United Nations drug control regime substantially interferes with the capacity of states to broaden drug availability for legitimate public health purposes. 
Reconceptualizing the drug control regime in a broader public health context may make an important contribution to efforts to advance pain relief worldwide.

\section{The International Legal Framework for Narcotics Control}

International drug control, including the control of opium, was one of the earliest fields of international cooperation. Crude opium has been available for thousands of years, but with the expansion of British opium trade in Asia in the 18th and 19th centuries and the development of the hypodermic syringe in the late 1860s, the abuse of opioids rose dramatically. By the late 19th century, global concern with opium consumption and trade reached a critical juncture, which led to public and professional pressure to restrict medical access to opioids for pain relief. These circumstances provided the backdrop for the first international cooperative arrangements for drug control that began to emerge in the early part of the 20th century. ${ }^{37}$ In 1909, the first International Opium Commission was convened in Shanghai, China, and it served as the platform for the first international legal instrument regulating psychoactive substances, the Hague Opium Convention of 1912.

The multilateral drug control regime has evolved over the last hundred years into a highly complex regulatory morass involving multiple treaties and international organizations. The scope of control over drugs has also broadened and deepened over time, both substantively and conceptually. Substantively, the list of drugs regulated has grown to include not just opium and cocaine, but also a range of newer psychotropic substances. Conceptually, the goals of the regime have shifted from an initial focus on the regulation and trade of drugs with legitimate medical purposes to a more recent emphasis on fostering multilateral cooperation to address the problems associated with licit and illicit drug abuse. ${ }^{38}$

The key multilateral drug conventions in force today are the 1961 United Nations Single Convention on Narcotic Drugs, the 1971 United Nations Convention on Psychotropic Substances, and the 1988 United Nations Convention Against the Illicit Traffic in Narcotic Drugs and Psychotropic Substances. The centerpiece of United Nations drug control regime, and of particular importance to the global availability of powerful opioid analgesics, is the Single Convention, which regulates narcotics including morphine and drugs with similar effects. The treaty regime has been remarkably influential in standardizing national drug laws, with some important exceptions, particularly in the realm of "harm reduction" efforts discussed below. As of 2005, 183 nations are party to the Single Con- vention, ${ }^{39}$ while other states and territories that are not formally party to the instrument comply with its terms, ${ }^{40}$ leaving only a handful of states outside the reach of the global drug regulatory ambit.

The twin aims of the Single Convention, as specified in its preamble and text, are to control the use and trafficking of substances with abuse potential while assuring the availability of these drugs for scientific and medical purposes. Assuring availability of drugs for scientific and medical purposes is of first importance in the text of the 1961 Single Convention. ${ }^{41}$ As described below, the Convention sets forth detailed obligations for State Parties and relevant international organizations to limit exclusively to medical and scientific purposes the production, manufacture, export, import, distribution, trade, use, and possession of drugs in order to achieve the core aims of the instrument.

The Single Convention emphasizes plant-based drugs such as opium, heroin, cannabis, and cocaine and classifies narcotic drugs according to their danger to health, risk of abuse, and therapeutic value. It establishes four schedules for controlled substances, with Schedule 1, applicable to morphine and drugs with similar effects and constituting the "standard regime of the Single Convention." ${ }^{42}$ Schedule 1 contains substances that are subject to all of the control provisions of the treaty. Key features of the Schedule 1 treaty regime include the limitation to medical and scientific purposes of all phases of narcotics trade (manufacture, wholesale and retail domestic trade, and international trade) and of the possession and use of drugs.

The Single Convention seeks to control illicit trade and abuse through stringent regulation of all phases of the supply of drugs. Government authorization (licensing and state ownership) is mandatory for participation in any phase of narcotics trade, and each individual international transaction requires an export or import license. A centerpiece of the Single Convention is a global "estimates" system designed to limit the total quantities of drugs, whether produced domestically or imported, available in each country on an annual basis, to that needed for medical and scientific purposes. The treaty also requires that every participant keep detailed records of all transactions in drugs and submit annual and quarterly statistical reports.

A complex network of international organizations and agencies has the responsibility of implementing the treaty. Most importantly, Article 9 of the Single Convention establishes the International Narcotics Control Board (INCB) as the lead organ of the Single Convention regime with the authority to monitor and 
promote the application of the Single Convention by State Parties. ${ }^{43}$ The 53-member Commission on Narcotic Drugs (CND) - the central drug policy making body in the United Nations system that is an organ of the Economic and Social Council (ECOSOC) - has specific authority pursuant to the Single Convention to add, remove, and transfer drugs among the treaty's four schedules of controlled substances. Any changes by the CND to drug scheduling under the Single Convention must be made in accordance with the findings and the recommendations of WHO. The CND may also make recommendations to the INCB and nonparties in order to promote the implementation of the Single Convention. Finally, the United Nations Office on Drugs and Crime (UNODC), of which the INCB's Secretariat is a part, is charged with the day-to-day responsibility of monitoring national compliance with the treaty.

\section{Public Health and the Prohibitionist Bias of the Global Drug Control Regime}

The international institutions that have collective responsibility to implement the aims of the Single Convention, the CND, the INCB, and UNODOC, have emphasized a strict drug prohibitionist and law enforcement approach to treaty interpretation and application in an to effort bolster global action to counter the extraordinary challenge of drug abuse worldwide. The sheer size of the global public health burden caused by drug trafficking and consumption is daunting. Illicit drugs alone are estimated to be one of the world's largest trading sectors. At $\$ 400-\$ 500$ billion per year, illicit trafficking in narcotics constitutes nearly ten percent of world trade and is larger than the automobile market. ${ }^{44}$ The United Nations Office on Drugs and Crime estimates that heroin is abused in three-fourths of all countries, and cocaine is abused in two-thirds. ${ }^{45}$ Drug trafficking has been linked to terrorism and organized crime, and drug-related problems include increased rates of crime and violence, susceptibility to HIV/AIDS and hepatitis, and a breakdown in social behavior. ${ }^{46}$

Countering the global burden of drug abuse and trafficking is an extraordinary global public health challenge. However, the operation of the international narcotics regime and, in particular, the strict prohibitionist approach of the international institutions charged with implementing the aims of the Single Convention, have been subject to a multiplicity of criticisms. Numerous commentators, for example, emphasize that the law enforcement approach to drug abuse has, in fact, failed to curb abuse and illicit trafficking. ${ }^{47}$ Illicit drug abuse was a public health concern in about 20 to 30 states when the Single Convention was adopted in 1961. Today, 46 years after the adoption of the treaty and the establishment of the contemporary regime for global control, illicit drug abuse has skyrocketed worldwide, with the total number of drug abusers between the ages of 15 and 64 estimated to be around 200 million. 48

Critics of the global drug control regime also posit that the traditional criminal justice approach to drug control (emphasized by the United Nations agencies) is at odds with the contemporary public health practice aimed at reducing drug abuse and its adverse consequences. In particular, observers argue that focusing the principal goal of drug policy on prohibition has diverted attention away from treatment and towards punishment. Countries such as Brazil, Canada, New Zealand, Australia, and member states of the European Union increasingly favor a "harm reduction" approach to drug abuse, including the use of injecting rooms, needle/syringe exchange programs, individual possession of cannabis for medical purposes, and substitution or maintenance treatment. However, the shift in priorities to "harm reduction" is increasingly seen by the INCB as covertly undermining prohibition. The polarized debate between the INCB, with its prohibitionist, criminalization perspective, and those governments wishing to pursue a "harm reduction" approach to drug control, is aired yearly at the annual meeting of the INCB. ${ }^{49}$ Although State Parties argue that such practices are consistent with the international law, the INCB, in its annual report, frequently criticizes such public health practices as conflicting with the letter and the spirit of the Single Convention..$^{50}$

Although it has received highly limited public and media attention, the strict criminal justice approach to treaty interpretation and application advanced by the global drug agencies also impinges significantly on the legal and political capacity of states to ensure access to pain medication for legitimate medical purposes. As described above, enhancing medical availability of opioids is one of the twin goals of the Single Convention along with the control of drug abuse. The preamble of the Single Convention recognizes that "the medical use of narcotic drugs continues to be indispensable for the relief of pain and suffering and that adequate provision must be made to ensure the availability of narcotic drugs for such purposes." ${ }^{\text {11 }}$ Medical availability of controlled substances is also a general obligation of the State Parties. Article 4(c) provides that Parties shall undertake legislative and administrative measures to "limit exclusively to medical and scientific purposes the production, manufacture, export, import, distribution of, trade in, use and possession of drugs." 52 Medical availability of morphine and other opioid analgesics is, therefore, a cardinal 
aim of the Single Convention and a core obligation of the Parties.

Implementing the aims of the Single Convention, including ensuring medical availability of morphine and other opioid analgesics, is a principal responsibility of the INCB. The INCB is mandated pursuant to Article 9(4) to cooperate with State Parties to "limit the cultivation, production, manufacture and use of drugs to an adequate amount required for scientific and medical purposes, to ensure their availability for such purposes and to prevent illicit cultivation, pro- scheduling of narcotics under the Single Convention. Pursuant to Article 3, the Single Convention establishes a unique and expeditious international legal process for adding a substance or changing the status of a substance under the treaty's four schedules without requiring a formal amendment to the Convention. First, the Single Convention authorizes WHO to conduct a medical and scientific review of a substance and to make a scheduling recommendation to the Commission on Narcotic Drugs. Second, the CND has the final decision to schedule the substance, but may do so

Concerned that legitimate medicines can be diverted into illicit channels, the International Narcotics Control Board has prioritized strict regulation of opioid analgesics in policy and practice. This has, concomitantly, relegated issues of medical availability to secondary consideration. Consequently, the INCB has not advanced any interpretation or application of the Single Convention in a manner that fulfills its obligation of advancing worldwide access to drugs for legitimate medical purposes.

duction, and manufacture of, and illicit trafficking in and use of, drugs."53 (Emphasis added.) The INCB has, in fact, undertaken studies and surveys on medical availability ${ }^{54}$ and, in its annual reports, the INCB has generally called upon nations to revise restrictive laws that interfere with opioid availability for medical purposes and that are in excess of the Single Convention's requirements.

Despite its rhetorical commitment to medical availability, in its operational activities and programmes, the INCB, along with the Secretariat that supports its work, views its mission as primarily one of law enforcement and drug control. Concerned that legitimate medicines can be diverted into illicit channels, the INCB has prioritized strict regulation of opioid analgesics in policy and practice. This has, concomitantly, relegated issues of medical availability to secondary consideration. Consequently, the INCB has not advanced any interpretation or application of the Single Convention in a manner that fulfills its obligation of advancing worldwide access to drugs for legitimate medical purposes.

Lessons from the Scheduling of Narcotic Drugs under the Single Convention: A Case Study of the Neglect of Medical Availability in International Practice

The most notable examples of the INCB's prohibitionist bias negatively impacting legitimate availability of pain medication for populations worldwide involve the only in accordance with the schedule recommended by WHO. This two-part review and scheduling process affects the controls that will be placed on medicines in each country pursuant to the Single Convention. As the Single Convention is widely adhered to, the scheduling decisions are of tremendous importance to the accessibility of drugs.

The scheduling process, including the rescheduling of substances already under international control, can have a substantial and unintended negative impact on medical availability of drugs worldwide. ${ }^{55}$ The regulatory requirements for drugs that are scheduled or rescheduled under the Single Convention can be tremendously burdensome and, at times, can outstrip the capacity of poor countries. Instituting the complex and extensive regulatory requirements mandated by the Single Convention for a scheduled substance is not a simple or perfunctory undertaking. Drafting and implementing effective national drug regulation necessitates technical skill as well as legal, financial, and technical capacity. It is widely appreciated that because of the regulatory burden imposed by the Single Convention, many poor states simply ban a medicine that may have important public health purposes when the substance is scheduled or rescheduled. Consequently, it is critically important to ensuring medical availability of legitimate medicines that scheduling decisions are based on solid medical, scientific, and public health information. 
In a number of recent cases involving scheduling or rescheduling under the Single Convention, the INCB and its Secretariat have promoted the interpretation and application of the treaty in a manner that reflects not only their overriding concern with law enforcement and drug diversion, but also neglect for medical availability considerations. One such case is the recent controversy involving the medical availability of ketamine a commonly used and essential analgesic in many states. In its 2006 annual report, the INCB urged countries to gather information on the abuse of ketamine, in order to assist WHO in considering scheduling the medication for tighter control. ${ }^{56}$ Concerned with the possible diversion of this medicine into illicit channels, the INCB also urged national governments reporting ketamine abuse to add the medicine to their national lists of controlled substances. ${ }^{57}$ The INCB took this action despite having, as described above, no legal jurisdiction in the scheduling process and knowing that scheduling can have a severe negative impact upon availability for legitimate medical purposes.

At the 2007 annual meeting of the Commission on Narcotic Drugs (CND), the WHO representative stated that he was "astonished" by the INCB's "heartless" call to states to schedule the essential medicine. ${ }^{58}$ WHO has the sole responsibility to conduct the medical and scientific evaluation of drugs and make recommendations on their scheduling to the CND. In March 2006, a WHO Expert Panel on Drug Dependence formally evaluated ketamine and did not recommend scheduling the substance. ${ }^{59}$ According to WHO, in resource-poor settings, ketamine can be the only substance available for anesthesia. Populations of many developing countries crucially depend upon access to ketamine for surgery, and the medication is part of WHO Guidelines for surgery in health care settings with limited technical resources. Given that many countries simply ban a medication subject to scheduling or rescheduling, the INCB's unauthorized and ill-considered call on states to schedule ketamine, based upon the mere possibility of abuse and without credible medical and scientific evidence, means that many patients in developing countries will not have access to surgery or will have to undergo surgery fully conscious. Notably, in the 2007 CND annual report, the controversy surrounding ketamine and WHO's striking intervention was not even mentioned. ${ }^{60}$

The case of ketamine is an important example of how greatly exaggerated concerns about drug diversion have led global drug regulatory authorities to advance drug scheduling decisions with severe public health consequences, without appropriately weighing the impact of scheduling on the legitimate medi- cal availability of a critical medicine. There are other such examples of the INCB's prohibitionist bias in the scheduling process, including buprenorphine, an important analgesic in many developing countries. ${ }^{61}$

The case of ketamine is also an important example of how greatly exaggerated concerns about drug diversion have led the INCB to seek to undermine the legitimate legal authority of WHO to make independent scheduling recommendations to the CND.

As described above, WHO has the sole responsibility to conduct the medical and scientific evaluation of drugs and make recommendations to the CND concerning the level of international control to be applied. Under the Single Convention, WHO has an established review process for scheduling recommendations in which an Expert Committee on Drug Dependence (WHO Expert Committee) evaluates substances for international control recommendations, pursuant to WHO Guidelines for the WHO Review of Dependence Producing Substances for International Control (Scheduling Guidelines).62 Following the substantive and procedural requirements set forth in the Guidelines, the WHO Expert Committee makes a scheduling recommendation to the WHO Director-General, who has final authority to make a scheduling recommendation to the CND.

Pursuant to the Single Convention and its constitutional mandate, WHO has broad authority to consider all relevant scientific and public health considerations when making a drug scheduling and rescheduling recommendation, including liability for abuse and medical availability. The Official Commentary to the Single Convention indicates that the impact of scheduling narcotics on medical availability should be an important and appropriate consideration during the WHO scientific review process. The Official Commentary to Single Convention Article 3, the treaty provision that addresses changes in the scope of control of substances, provides that WHO has "wide discretion" in the scheduling process and should be "guided in this choice by the interests of public health in each case, as it appears not only from the degree of danger which the substance in question presents but also from the need to make useful medicines as easily available as may be compatible with the requirements of their control."63 The WHO scientific review process established under the Single Convention is designed to permit a rigorous and evidence-based evaluation of medicines that balances risks of abuse against the benefits obtained through legitimate use. The scientific and public health approach to drug scheduling recommendations undertaken as part of the WHO review process, the first step in the scheduling process, also provides a critical counterpoint and public health bal- 
ance to the more politicized forum of the Commission on Narcotic Drugs.

The INCB's efforts to focus the scheduling process exclusively upon questions of abuse by, among other things, undermining the legal authority and responsibility of WHO to provide an evidence-based analysis for drug-scheduling recommendations raise important concerns. The INCB Secretariat's apparent perspective that the impact of drug scheduling on medical availability should not be a central consideration in the scheduling process is inconsistent with the text of the Single Convention. Furthermore, as in the case of ketamine, the INCB's single-minded prohibitionist perspective could result in the placement of inappropriate controls on legitimate medicines. Far from solving a public health problem, the prohibitionist bias of INCB and the other drug regulatory agencies is preventing legitimate patients from being prescribed medication that they desperately need.

\section{Achieving Balance in Global Regulatory Drug Policy}

In their efforts to fight global drug trafficking and abuse, the international drug regulatory agencies have adopted a narrow view of the public health objective ing to WHO, "The Central Principle of Balance" represents the dual imperative of preventing the abuse, trafficking, and diversion of narcotic drugs while, at the same time, ensuring medical availability. As stated by WHO, "When misused, opioids pose a threat to society; a system of control is necessary to prevent abuse, trafficking, and diversion, but the system of control is not intended to diminish the medical usefulness of opioids, nor interfere in their legitimate medical uses and patient care." 65

The concept of the Central Principle of Balance should not be limited to national regulatory policies, but should also guide the development and implementation of international drug control policies. This article has illustrated that the current worldwide system for drug control poses important risks to global public health. In addition, the prohibitionist bias of the international drug regulatory agencies may also undermine the goal of drug control by exacerbating the problem of the diversion of licit medicine into illegal channels.

As a general matter, the risk of diversion of licit medicines into illegal traffic has not traditionally been one of the most critical challenges in international drug control. Although the global drug regime has been sin-

\section{Although not technically binding, the increasing number of intergovernmental resolutions adopted by the General Assembly and other international forums reflects the world community's growing recognition of the critical link between access to essential medications and human rights. The specific reference to the link between palliative care and human rights may reflect the community's emerging recognition that allowing millions to suffer preventable excruciating pain is an affront to human dignity.}

of global drug control. Consistent with the twin aims of the Single Convention, public health in the drug regulatory context is appropriately understood in a broader context as encompassing efforts that both guarantee legitimate access to pain medication for patients in need as well as control abuse and diversion. Reconceptualizing the drug control regime and realigning the efforts of drug regulatory organs to this public health perspective may make an important contribution to efforts to advance pain relief worldwide.

In 1998, WHO, in cooperation with its collaborating center at the University of Wisconsin, elaborated the concept of the "Central Principle of Balance" in order to guide the development of national drug regulatory policies pursuant to the Single Convention. ${ }^{64}$ Accord- gularly unsuccessful in curbing abuse of illicit drugs, it has been remarkably effective in curbing production and diversion of licit narcotic drugs, ${ }^{66}$ particularly opioid-based analgesics. The United Nations Office on Drugs and Crime estimates that global opium production today is 80 percent of what it was almost 100 years ago. ${ }^{67}$ As late as 2006, there were no cases of the diversion of narcotic drugs from licit to illicit international trade. ${ }^{6} 8$

Recently, however, the INCB has reported an increasing problem of the diversion of licit opioid analgesics in domestic markets, particularly in the United States and Canada. ${ }^{69}$ The Board has recognized that overly stringent national drug control regulations, such as complex prescription requirements, can obstruct the 
capacity of legitimate patients to get essential pain relief. This, in turn, is contributing to the growth of the unregulated market in licit medicines since desperate patients turn to illicit channels to obtain pain relief that they cannot obtain through legal sources. To the extent that the operation of the international control regime contributes to the problem of excessive national drug regulation, as in the case of the scheduling of analgesics described above, the efforts of the global drug control agencies may, in fact, be contributing to the growing problem of the diversion of licit medication.

Using the Central Principle of Balance to advance the dual purposes of the Single Convention is consistent with international human rights law. Access to essential medicines, including pain medicine, is receiving increasing recognition in the practice and praxis of international human rights law. In the context of pandemics such as HIV/AIDS, tuberculosis, and malaria, the United Nations General Assembly in 2004 adopted a resolution recognizing that access to medication is a "fundamental element for achieving progressively the full realization of the right of everyone to the enjoyment of the highest attainable standard of physical and mental health." ${ }^{\circ 0}$ In this resolution, the General Assembly specifically identified a link between pain medicine and human rights when it called upon states to adopt legislation to safeguard and promote effective access to "preventative, curative or palliative pharmaceutical products." ${ }^{11}$ (Emphasis added.) A similar resolution was adopted in the Commission on Human Rights..$^{72}$ Although not technically binding, the increasing number of intergovernmental resolutions adopted by the General Assembly and other international forums reflects the world community's growing recognition of the critical link between access to essential medications and human rights. The specific reference to the link between palliative care and human rights may reflect the community's emerging recognition that allowing millions to suffer preventable excruciating pain is an affront to human dignity.

Rethinking the Single Convention: Advancing Access to Pain Medication through the Implementation of International Law

This article has illustrated that advancing public health and protecting human rights in the international drug regulatory context requires policymakers to elaborate a new and more balanced approach to global drug control. In particular, this new approach to implementation must depart from the strict prohibitionist approach that dominates the agenda of the global drug regulatory authorities today. Policymakers must articulate a comprehensive and holistic approach to drug control that balances the dual aims of the Single Convention: preventing abuse and ensuring medical availability.

Reconceptualizing implementation of the Single Convention to achieve greater balance in global drug policy can make an important contribution towards increasing access to pain medications. The INCB, and the Secretariat that supports its work, are of particular importance if more effective implementation of the treaty is to be achieved. The INCB, in particular, exists to promote governments' application of drug treaty provisions.

Research over the last decade and a half by scholars of international relations and international law clearly evidences that international institutions can produce dramatic changes in the behavior of the states and non-states that they seek to influence. ${ }^{73}$ In other words, international organizations, through the operation of treaty provisions, can help make treaties work. The INCB can undertake a number of steps pursuant to the Single Convention to encourage and assist State Parties in strengthening access to medicines. Most importantly, the INCB can advance an interpretation of the scheduling process that supports legitimate medical access to opioid analgesics. More generally, the INCB can encourage states to strengthen national medical availability policies by utilizing its legal authority to monitor and implement the dual aims of the Convention.

It is widely appreciated that supervision of national compliance with international norms by international institutions can help promote rule compliance by states. International institutions can promote national implementation of international obligations by enabling states to be held accountable to other states and, at times, the wider public, thereby exercising a form of collective community supervision. ${ }^{74}$ International monitoring and supervision of compliance with state obligations is of primary importance to international treaty implementation in a wide range of fields, including the environment, human rights, and arms control. ${ }^{75}$ In contrast, the absence of any provision for institutional review has often been recognized as a sign that a treaty is ineffective and at risk of becoming obsolete. ${ }^{76}$

The Single Convention incorporates several rigorous international supervisory and non-compliance mechanisms to promote national implementation consistent with the aims of the Convention. Notably, these mechanisms have been widely used by the INCB to monitor national efforts to prevent drug abuse and trafficking, as well as to critique "harm reduction" policies favored by some states. However, the procedures 
have not been employed to monitor and promote state action on medical availability.

Consistent with contemporary treaty practice, the Single Convention incorporates a reporting mechanism. Most treaties today require State Parties to make periodic reports on matters affecting the treaty. While the extent of the obligation varies, reporting procedures generally require State Parties to submit national reports on the measures that they have adopted and the headway that has been made in implementing a treaty. Pursuant to Article 18 of the Single Convention, State Parties are required to provide such an annual report. Parties, pursuant to Article 19, are also legally obligated to submit other information to the Board, including estimates of drug requirements and a host of statistical information on the production, manufacture, use, imports, and exports of drugs.

The Board has broad authority to engage in a dialogue with states on the consistency of the measures reported, as related to the objectives of the Single Convention. It is also authorized to publicly disclose state activity and to critically analyze such measures in the annual INCB report or in other reports. Article 15 of the Single Convention empowers the INCB to include in its reports "an analysis of the estimates and statistical information at its disposal and, in appropriate cases, an account of the explanations if any, given by or required of Governments, together with any observations and recommendations which the Board desires to make."77 Pursuant to its mandate under the drug control treaties, the Board also regularly selects several countries for review, with the goal of analyzing their overall compliance with the provisions of the drug control conventions. The findings of the review, as well as the Board's recommendation for remedial action, are conveyed to the State Parties individually and are generally discussed in the annual INCB report.

Periodic reporting of states' performance can be an important mechanism in assisting states to identify and alleviate obstacles when implementing international commitments. ${ }^{78}$ Reporting functions can thus help to raise domestic bureaucratic conscience about treaty obligations. This regular review can provide the basis for the elaboration of clearly stated and targeted policies. Periodic review can also expand the community of interest by facilitating public scrutiny of governmental policy. Consequently, a periodic review process can generate domestic pressure to comply with a treaty's terms. In addition, a monitoring process can open a dialogue between national officials and the monitoring organization, thereby helping states to understand the requirements of the treaty and to proactively identify domestic difficulties with compliance.
Finally, a reporting process can assist State Parties in implementing international obligations by triggering international assistance to solve domestic problems identified during the reporting process.

In implementing the periodic reporting procedure, the INCB has established a highly effective reporting process with stringent critical review of national conduct. The INCB achieves almost universal reporting compliance by State Parties and non-parties because the manufacture, import, export, and medical use of opioids are determined by the Board through the estimates system. Additionally, compliance with the institutional reporting process is enhanced because control of illicit narcotics is high on the criminal justice and political agendas of states. ${ }^{79}$ However, though the INCB has utilized the reporting process to advance provisions of the treaty related to drug abuse and trafficking, the Board has not generally sought to use the uniquely effective reporting process to encourage states to fulfill their treaty obligation to ensure medical availability of opioid analgesics.

In order to advance implementation of drug control and trafficking under the Single Convention, the INCB also conducts periodic missions to State Parties in order to review the national drug control situation. The INCB reports the results of its inspections and recommendations made to states in its annual report, and about 20 such missions are conducted annually. Inspections to verify treaty compliance are generally considered the strongest method of information gathering and supervision in the international system and can be a powerful means to encourage rule compliance. ${ }^{80}$ The strongest examples of inspection by international agencies are in arms control. The inspection regime can be used to promote public health by encouraging states to implement their treaty commitments on medical availability. However, as in the case of the periodic reporting mechanisms, the inspection procedure has not generally been conceived of or used as a tool to advance equitable access to desperately needed pain medication.

The Single Convention also incorporates a potent non-compliance procedure designed to secure conformity with the terms of the treaty. Non-compliance procedures are generally an extension of the information gathering, monitoring, and supervision processes, as they represent a stronger means of inducing states to comply. ${ }^{81}$ Non-compliance procedures can be understood as a soft form of dispute settlement that can pressure errant states into rule compliance. Article 14 of the Single Convention incorporates a range of assertive mechanisms in order to encourage noncompliant states to meet their obligations under the Single Convention. First, the INCB has the power to 
propose consultations, request explanations, and recommend that a government modify its policies if the Board has objective reason to believe that the "aims of this Convention are being seriously endangered by reason of the failure of any Party, country or territory to carry out the provisions of this Convention." 82 The Board can also, at its discretion, request an inspection in the territory to assess national policies.

If the INCB finds that a government has failed to furnish satisfactory explanations or adopt remedial recommendations suggested by the Board, or if there is a serious situation that needs international cooperative action, then it can widely publicize the noncompliance. In particular, the INCB can put national behavior under a spotlight by alerting the Parties, the Commission on Narcotic Drug, and the United Nations Economic and Social Council. The Board also has the right to publish a report on the matter. ${ }^{83}$

The Single Convention Article 14 non-compliance procedure could be a powerful tool for encouraging countries to effectively advance the treaty's objective of medical availability. The idea of utilizing the noncompliance procedure in cases where countries have not fulfilled their obligation to make essential medicines available may seem farfetched, but it is a reasonable and appropriate interpretation of the text of the provision. Article 31 of the Vienna Convention on the Law of Treaties, the treaty on treaties, sets forth that a "treaty shall be interpreted in good faith in accordance with the ordinary meaning to be given to the terms of the treaty in their context and in light of their object and purpose." 84 The context referred to means the treaty's preamble and annexes. Notably, Article 14.1.a. of the Single Convention provides that the non-compliance measures are triggered when the Board believes that the "aims" of the Convention are seriously endangered. As medical availability is one of the two core aims of the Convention established by the preamble and Article 4, the ordinary meaning of the language and the context of the treaty supports the interpretation. ${ }^{85}$ Clearly, the initiation of an Article 14 procedure is a very serious matter, and not all cases justify the imposition of this process. There could be cases requiring the procedure, however, such as when a country has consistently neglected to address the issue of pain relief and has failed to furnish the Board with any reasonable explanation.

Importantly, the mere threat of an Article 14 procedure by the INCB may induce governments to take corrective action and strengthen medical availability. Even if the government is not directly pressured by the threat of an Article 14 procedure, in democratic societies, the public and the media may exercise pressure for compliance. Unfortunately, as with both reporting and inspections procedures, the Board has neglected to use the non-compliance procedure of Article 14 to induce national action to ensure opioid medication for patients in need. Notably, the INCB has never utilized the Article 14 non-compliance procedure in a case of medical availability. ${ }^{86}$

Collectively, the reporting, inspection, and noncompliance procedures established under the Single Convention could be important mechanisms in encouraging countries to honor their legal obligation to expand medical availability of critical medicines. Interestingly, the Single Convention stands apart from many treaties with a strong public health component because of the potential strength of these procedures. Powerful implementation mechanisms, particularly non-compliance and inspection procedures, are fairly uncommon in the international system and rare in treaties with a significant public health component. The Single Convention inspection regime was established because of the strong linkage between criminal justice and drug abuse. The INCB's failure to use these procedures is contrary to the letter and spirit of the Single Convention and is a wasted opportunity in making an important impact on the global challenge of needless human pain.

Of course, monitoring and implementation are not the only international institutional mechanisms to support treaty adherence by State Parties. A variety of national factors account for compliance with international obligations, and not all violations are premeditated or purposeful. As a general matter, it is widely recognized that the failure of states to implement international commitments into national law and policy may reflect, to some degree, a limitation of capacity or capability, and not a lack of political will. ${ }^{87}$

This is certainly the case with medical availability of powerful analgesics. As described above, a lack of technical, legal, and bureaucratic capacity characterizes the drug regulatory framework in many countries and significantly obstructs advancing the availability of narcotics for pain relief. Working with WHO on its new Access to Controlled Medicines Programme could greatly assist states in meeting their legal obligation to ensure medical availability of opioids. The INCB and WHO could provide technical assistance to states in implementing standards on access to opioid medications, including strengthening national capacity to meet the regulatory requirements of the estimates system. ${ }^{88}$

Elements from other global regimes can also provide guidance in strengthening the implementation of the Single Convention to advance medical availability of essential pain medications. One critical area for strengthened national and international action 
is the financing and supply of opioid analgesics. As described above, one of the key obstacles to pain control in developing countries is the lack of availability of cheap, generic forms of morphine. Innovative approaches for addressing this public health dilemma are urgently needed. One possible approach would involve the collaboration of the INCB, UNODOC, and WHO to establish a global financing mechanism that would advance the universal availability of inexpensive generic forms of morphine. By using its purchasing power while carefully regulating availability and quality assurance, the INCB could solve one of the key obstacles to drug availability in poor states.

As the lead institution of the global drug regulatory regime, the INCB has an express legal obligation to advance the aim of the Single Convention in ensuring medical availability. By utilizing the reporting, inspection, and non-compliance mechanisms incorporated in the treaty, and by encouraging effective collaborations between UNODOC and WHO in providing technical and financial support to poor states, the INCB could make an unparalleled contribution to advancing universal availability of opioid medications. By working effectively with governments on this critical public health and human rights concern, the INCB may be able to address and alleviate the lack of national political commitment to effective pain control. The development of new national laws and policies on pain control may also, over time, contribute to a broadened understanding and acceptability of medicinal pain control among domestic populations. In other words, international action could trigger the implementation of national laws and policies that may contribute to expanding knowledge about pain medicine among patients and providers. This process can help to create a social climate in which pain relief is not only socially acceptable, but also universally recognized as an integral component of good clinical practice.

\section{Conclusion}

Today we have the knowledge and the experience to control pain and significantly diminish human suffering. The tragedy is that for most of the world's population effective pain control is entirely unavailable. Pain control is inexpensive, cost effective, and can be integrated into resource-poor settings. Yet the access gap between rich and poor countries continues to widen. The global public health and human rights challenge is to expand awareness and action, nationally and internationally, and to ensure equitable access to good pain control for all legitimate patients.

This paper has recommended an alternative approach to international drug control - one that is consistent with the Single Convention and that seeks to balance control of abuse with medical availability. Ultimately, political commitment, particularly among major donors to U.N. drug control efforts, will be the most essential component of a new drug control regime. Rethinking the Single Convention requires collective action by a group of countries with a shared reform agenda. Even with political support from key states, the complexity of the issues surrounding the pain matrix means that there is no magic policy pill that can ensure effective medical availability of opioids. However, national and international policies that balance concern of abuse and medical availability are critical components of advancing pain treatment worldwide.

\section{Acknowledgements}

The author gratefully acknowledges the support of the faculty, fellows, and students of the O'Neill Institute for National and Global Health Law at Georgetown University Law Center, including Dean Lawrence Gostin, Ben Berkman, Lauren Dunning, Meagan Winters, Stelios Xenakis, and Susan Kim. I am also grateful to Willem Scholten for his comments and guidance.

References

1. R. Webster, J. Lacey, and S. Quine, "Palliative Care: A Public Health Priority in Developing Countries," Journal of Public Health Policy 28, no. 1 (2007): 28-39.

2. World Health Organization, Single Convention on Narcotic Drugs, 1961, March 30, 1961, at Art. 21-24, available at $<$ http:// www.unodc.org/pdf/convention_1961_en.pdf> (last visited September 4, 2007).

3. World Health Organization, Access to Controlled Medications Programme: Briefing Note, Geneva, Switzerland, March 2007, available at <http://www.who.int/medicines/areas/quality_ safety/AccessControlledMedicationsBrNote.pdf $>$ (last visited September 4, 2007).

4. International Narcotics Control Board, Report of the International Narcotics Control Board for 2006, U.N. Doc. E/ INCB/2006/1, March 1, 2007, para. 67. Medical availability is also problematic in some wealthy countries, including Japan.

5. International Narcotics Control Board, Report of the International Narcotics Control Board for 2004, U.N. Doc. E/ INCB/2004/1, March 2, 2005, at para. 143.

6. See World Health Organization, supra note 2.

7. See Webster et al., supra note 1.

8. Id.

9. K. M. Foley, J. L. Wagner, and D. E. Jorganson et al., "Pain Control for People with Cancer and AIDS," in D. T. Jamison, J. G. Breman, and A. R. Meaham et al., eds., Disease Control Priorities in Developing Countries, 2nd ed. (Oxford: Oxford University Press \& World Bank, 2006): 981-93, at 982.

10. Since the 1970s, WHO has promoted equitable access to health services through the concept of essential medicines. Essential medicines are those that satisfy the priority health care needs of the population. They are selected with due regard to disease prevalence, evidence on efficacy, safety, and comparative costeffectiveness. Essential medicines are intended to be available at all times, in adequate amounts, in the appropriate dosage forms, with assured quality, and at a price the individual and the community can afford. See World Health Organization Expert Committee, The Selection and Use of Essential Medicines: Report of the WHO Expert Committee, 2005, WHO Technical Report Series No. 933, Geneva, Switzerland, 2006. Opioid analgesics on the WHO Model List of Essential Medicines include codeine tablet $30 \mathrm{mg}$; morphine injection $10 \mathrm{mg}+1-\mathrm{ml}$ 
amouple; morphine oral solution $10 \mathrm{mg} / 5 \mathrm{ml}$ and morphine table 10mg. $I d$., at 63.

11. B. E. Cole, "The Last Word: The State of Pain Management," FDA Consumer Magazine 38, March-April 2004, at 40.

12. International Narcotics Control Board, "Availability of Opiates for Medical Needs," in Report of the International Narcotics Control Board for 1995, United Nations, 1996; World Health Organization, Achieving Balance in National Opioids Control Policy: Guidelines for Assessment, WHO/EDM/QSM/2000.4, 2000.

13. Editorial, "Organization of Development of Pain Clinics and Palliative Care in Developing Countries," European Journal of Anesthesiology 21, no. 3 (2004): 169-72

14. J. Stjernswärd, "Palliative Care: The Public Health Strategy," Journal of Public Health Policy 28, no. 1 (2007): 42-55.

15. See Cole, supra note 11.

16. See World Health Organization, supra note 2.

17. Id.; R. C. Koshy, D. Rhodes, and S. Devi et al., "Cancer Pain Management in Developing Countries: A Mosaic of Complex Issues Resulting in Inadequate Analgesia," Support Cancer Care 6, no. 5 (1998): 430-37.

18. P. Farmer, Pathologies of Power: Health, Human Rights, and the New War on the Poor (Berkeley: University of California Press, 2005): xxiv-vii.

19. See Koshy et al., supra note 17.

20. Id.

21. See Webster et al., supra note 1.

22. L. De Lima and C. Sweeney et al., "Potent Analgesics Are More Expensive for Patients in Developing Countries," Journal of Pain and Palliative Care Pharmacotherapy 18, no. 1 (February 3, 2004): 59-70.

23. Id.

24. See World Health Organization, supra note 2; Koshy et al., supra note 17.

25. Editorial, "The Persistent Problem with Pain," The Lancet 357, no. 9264 (2001): 1217

26. See World Health Organization, supra note 2.

27. See Webster et al., supra note 1.

28. See World Health Organization, supra note 2; H. McQuay, "Opioids in Pain Management," The Lancet 353, no. 9171 (1999): 2229-32.

29. See Koshy et al., supra note 17.

30. See Webster et al., supra note 1.

31. See Stjernswärd, supra note 14.

32. See Koshy et al., supra note 17.

33. D. E. Joranson, M. R. Rajagopal, and A. M. Gilson, "Improving Access to Opioid Analgesics for Palliative Care in India," Journal of Pain Symptom Management 24, no. 2 (August 2002): 152-59.

34. Id.

35. $I d$

36. See World Health Organization, supra note 2; see also, W. Scholten, H. Nygren-Krug, and H. A. Zucker, "The World Health Organization Paves the Way for Action to Free People from the Shackles of Pain," Anesthesia \& Analgesia 105, no. 1 (July 2007): 1-4.

37. J. A. Costa e Silva, "Medicines and the Drug Control Treaties: Is Buprenorphine for Opioid Addiction at Risk of Being Lost?" Human Psychopharmacology 19, no. 4 (2004): 215-24.

38. Office on Drugs and Crime, World Drug Report 2006, Volume 1: Analysis, United Nations Sales No. E.06.XI.10, 2006, at 7.

39. International Narcotics Control Board, Report of the International Narcotics Control Board for 2005, U.N. Doc. E/ INCB/2005/1, March 1, 2006 at para. 50.

40. Interview with Pavel Pachta, Deputy Secretary of the Board and Chief Narcotics Control and Estimates Section, INCB Secretariat, United Nations Office on Drugs and Crime (September 12, 2006).

41. The first preambular paragraphs to the Convention provide that:

"The Parties: Concerned with the health and welfare of mankind, Recognizing that the medical use of narcotic drugs continues to be indispensable for the relief of pain and suffering and that adequate provision must be made to ensure the availability of narcotic drugs for such purposes, Recognizing that addiction to narcotic drugs constitutes a serious evil for the individual and is fraught with social and economic danger to mankind...." United Nations, Single Convention on Narcotic Drugs, as amended by the 1972 Protocol amending the Single Convention on Narcotic Drugs, 1961, at art. 1.

42. U.N. Secretary General, Commentary on the Single Convention on Narcotic Drugs, 1961, New York, 1973.

43. The Board consists of 13 members who are elected by the Economic and Social Council (ECOSOC). Three members with medical, pharmacological, or pharmaceutical experience are elected from a list of persons nominated by the World Health Organization (WHO), and ten members are elected from a list of persons nominated by the Members of the United Nations and by State Parties that are not Members of the United Nations, in accordance with Article 9 of the Single Convention. United Nations, Single Convention on Narcotic Drugs, as amended by the 1972 Protocol amending the Single Convention on Narcotic Drugs, 1961, at art. 9.

44. K. Raustiala, "Law, Liberalization and International Narcotics Trafficking," New York University Journal of International Law \& Politics 32 (Fall 1999): 89-145.

45. Office on Drugs and Crime, "Drug Abuse and Demand Reduction," available at <http://www.unodc.org/unodc/en/drug_ demand reduction.html $>$ (last visited October 10, 2007).

46. Id.

47. C. S. J. Fazey, "The Commission on Narcotic Drugs and the United Nations International Drug Control Programme: Politics, Policies and Prospect for Change," The International Journal of Drug Policy 14, no. 2 (2003): 155-69; D. R. Bewley-Taylor and C. S. J. Fazey, "The Mechanics and Dynamics of the U.N. System for International Drug Control," (2003) (unpublished document copy on file with author).

48. See Office on Drugs and Crime, supra note 38.

49. D. Bewley-Taylor, Emerging Policy Contradictions Between UNODC 'Universe' and the Core Values and Mission of the U.N., presentation at the First International Symposium on Global Drug Policy, Lisbon, Portugal, October 25, 2003, available at <http://www.senliscouncil.net/modules/events/lisbon/22_bewley-taylor> (last visited October 10, 2007).

50. International Narcotics Control Board, "Annual Report: By Year," available at <http://www.incb.org/incb/annual_report. html> (last visited September 4, 2007).

51. See World Health Organization, supra note 2, at Preamble.

52. Id., at art. 4 .

53. Id., at art. 9 .

54. International Narcotics Control Board, Report of the International Narcotics Control Board for 1995: Availability of Opiates for Medical Needs, U.N. Doc. E/INCB/1995/1, 1996, at para. 65.

55. See Costa e Silva, supra note 37; see World Health Organization, supra note 2.

56. International Narcotics Control Board, "Report of the International Narcotics Control Board for 2006," available at <http:// www.incb.org/incb/en/annual_report_2006.html> (last visited September 4, 2007).

57. See International Narcotics Control Board, supra note 4.

58. Intervention of Willem Scholten, WHO Technical Officer, to the Commission on Narcotic Drugs, 2006, as referenced in supra note 56. (A copy of the intervention is on file with the author.)

59. See International Narcotics Control Board, supra note 4, at para. 202.

60. Commission on Narcotic Drugs, Report on the Fiftieth Session, U.N. Doc. E/2007/28 and E/CN.7/2007/16, March 17, 2006 and March 12-16, 2007.

61. See Costa e Silva, supra note 37.

62. World Health Organization, Guidelines for the WHO Reviere of Dependence-Producing Psychoactive Substances for International Control, WHO Doc. WHO/EDM/QSM/2000.5, 2000. 
63. See World Health Organization, supra note 3, at 44 .

64. Pain \& Policy Studies Group, University of Wisconsin Comprehensive Cancer Center, and World Health Organization Collaborating Center for Policy and Communications in Cancer Care, "Resources for Addressing Barriers to Pain Relief in the World," available at <http://www.painpolicy.wisc.edu/internat/conf_materials/Seoul/seoul_resources.pdf > (last visited September 4, 2007); D. E. Joranson, "Improving Availability in Opioid Pain Medications: Testing the Principle of Balance in Latin America," Innovations in End of Life Care 5, no. 1 (January-February 2003), available at <http://www2.edc.org/ lastacts/archives/archivesJan03/featureinn.asp> (last visited October 10, 2007).

65. Id. (Pain \& Policy Studies Group), supra note 64.

66. B. Leroy, International Drug Policy: Challenges and Perspectives, presentation at the First International Symposium on Global Drug Policy, Lisbon, Portugal, October 25, 2003, available at <http://www.senliscouncil.net/modules/events/lisbon/17 leroy> (last visited October 10, 2007).

67. See Office on Drugs and Crime, supra note 38.

68. See International Narcotics Control Board, supra note 5.

69. Id

70. U.N. General Assembly, Access to Medication in the Context of Pandemics Such as HIV/AIDS, Tuberculosis and Malaria, G.A. Res. 58/179, U.N. Doc. A/RES/58/179, March 17, 2004, available at <http://daccessdds.un.org/doc/UNDOC/GEN/N03/505/32/ PDF/N0350532.pdf?OpenElement> (last visited September 4, 2007). The link between access to medicines and human rights has also been identified by the Committee on Economic, Social and Cultural Rights in General Comment No. 14 to Article 12 of the Covenant on Economic, Social and Cultural Rights, which establishes the right to health. In the Committee's view, Article 12(a) recognizes that the right to health contains a number of essential elements, including essential drugs as defined by the WHO Action Programme on Essential Drugs. As discussed above, the WHO Model List of Essential Medicines includes commonly used and critical opioid analgesics.

71. Id., at 4 .

72. U.N. Commission on Human Rights, Access to Medication in the Context of Pandemics Such as HIV/AIDS, Tuberculosis and Malaria, C.H.R Res. 2003/29, U.N. Doc. E/CN.4/ RES/2003/29, April 22, 2003.
73. A. Chayes and A. H. Chayes, The New Sovereignty (Boston: Harvard University Press, 1995): 273-85; R. B. Mitchell, "Of Course International Institutions Matter: But When and How?” in F. Biermann, R. Brohn, and K. Dingwerth, eds., Proceedings of the 2001 Berlin Conference on the Human Dimensions of Global Environmental Change: Global Environmental Change and the Nation State (Potsdam: Potsdam Institute for Climate Impact Research, 2002): 16-25; A. Taylor, "Making the World Health Organization Work: A Legal Framework for Universal Access to the Conditions for Health," American Journal of Law and Medicine 18, no. 4 (1992): 301-46; R. Keohane, "International Institutions: Two Approaches," in R. Beck, A. C. Arend, and R. D. Vander Lugt, eds., International Rules (New York: Oxford University Press, 1995): 187-205.

74. P. W. Birnie and A. Boyle, International Law and the Environment, 2nd ed. (Oxford: Oxford University Press, 2002): at 201.

75. A. Taylor, "Globalization and Biotechnology: UNESCO and an International Strategy to Advance Human Rights and Public Health," American Journal of Law and Medicine 25, no. 4 (1999): 479-541, at 514 .

76. See World Health Organization, supra note 2, at art. 15.

77. See Birnie and Boyle, supra note 74 .

78. Id.; P. Szasz, ed., Administrative and Expert Monitoring of International Treaties (Yardsley, NY: Transnational Publishers, 1999): at 15.

79. See Patcha, supra note 40.

80. See Birnie and Boyle, supra note 74

81. Id.

82. See World Health Organization, supra note 2, at art. 14 .

83. The INCB also has the authority to recommend to State Parties that they stop the import of drugs, the export of drugs, or both from or to the country concerned, if it is satisfied that such a course is necessary. This remedy, however, does not seem to be an appropriate recommendation in the context of countries that are neglecting opioid analgesics, and appears designed for cases in which failure to control illicit traffic poses an international risk.

84. Vienna Convention on the Law of Treaties, January 27, 1980, 1155 U.N.T.S. 331, at art. 31

85. Id.

86. Id., at art. 14 .

87. See Chayes and Chayes, supra note 73.

88. See Vienna Convention, supra note 84. 